INTERNATIONAL JOURNAL OF RESEARCHES IN BIOSCIENCES, AGRICULTURE AND TECHNOLOGY (c) VISHWASHANTI MULTIPURPOSE SOCIETY (Global Peace Multipurpose Society) R. No. MH-659/13(N) www.ijrbat.in

\title{
EVALUATION OF ANTIFUNGAL POTENTIAL OF ENDOPHYTIC FUNGUS PREUSSIA ISABELLAE ISOLATED FROM AZADIRACHTA INDICA
}

\author{
Vaishali A. Fulzele*, Asifa Qureshi** and A.A. Fulzele*** \\ *Shri Shivaji Science College, Congress Nagar, Nagpur 440012 Maharashtra, India \\ **Environmental Genomics Unit, National Environmental Engineering Research Institute (CSIR), Nehru \\ Marg, Nagpur 440 020, Maharashtra, India. E- mail: a_qureshi@neeri.res.in \\ ***Shri Mathuradas Mohota College of Science, Umred Road, Nagpur 440009 Maharashtra, India. \\ Corresponding Author : ashwajitfulzele@gmail.com
}

\begin{abstract}
:
Azadirachta indica (Neem tree) harbors fungal endophytes that are continuously screened for their useful secondary metabolites including with antimicrobial potential. This investigation deals with an endophytic fungus Preussia isolated from Neem tree, evaluated for lovastatin production and was analyzed for its antimicrobial potential. The endophyte was identified as Preussia isabellae evaluated for its antifungal activity. Culture extract from $P$. isabellae shows prominent inhibition against Sacchromyces cerevisiae. Neem tree is important source of endophyte with antifungal potential.
\end{abstract}

Keywords: Azadirachta indica, endophyte, lovastatin, antifungal, Preussia..

\section{INTRODUCTION:}

Endophytes are the micro-organisms that are symbiotically associated within the plants, at all or some phase of their life cycle. Endophytic fungi are the rich source of secondary metabolites which shows varying bioactivities like antiviral, antifungal, antibacterial, antioxidants, ant insecticidal and immunosuppressant (Strobel 2003; Tejesvi 2007).

Lovastatin is one of the important secondary metabolite obtained from fungi with hypocholesterolemic potential. Lovastatin treatment has shown reduction in prevalence of Alzheimer's disease. Apart from that lovastatin helps to prevent kidney related disorders and shows antifungal activity (Buemi, 2002).

Azadirachta indica commonly known as Indian lilac is known for its medicinal properties. Studies have been carried out that indicate Azadirachta indica harboring endophytic fungi and such endophytes showing properties of secretion of pharmaceutically important secondary metabolites, (Kharwar 2009).

Present investigation an attempt has been made to isolate the endophytic fungi from Azadirachta Indica and extract lovastatin and evaluate its antifungal activity.

\section{MATERIALS \& METHOD:}

Isolation of fungal endophytes from leaves of the Azadirachta Indica (Neem tree): Leaves of Neem tree were surface sterilized and placed on sterile plates with nutrient medium Potato Dextrose Agar (PDA) supplemented with antibiotic chloramphenicol to avoid bacterial contamination. The plates when incubated at $27^{\circ} \mathrm{C}$, fungal colonies start appearing after 5 days, that are separated and pure endophytic fungi were isolated following incubation (Schulz et al 1993).

\section{Identification of Endophytic fungi:}

Isolated pure culture was examined and identified by both for morphological and colony characteristics, identification confirmed with the help of standard literature.

Solid state fermentation and lovastatin extraction:

Spore suspension of seven days old pure culture of selected fungal endophyte was inoculated in sterilized wheat bran in Erlenmeyer flask to carry out solid state fermentation, with moisture content of medium maintained to $70 \%$. The experiment was set in triplicates with one control without fungi and incubated at $25^{\circ} \mathrm{C}$ for 10 days of solid state fermentation. Fungal extract was prepared by ethyl acetate extraction, the extract was evaporated and dissolved in acetonitrile and used for further analysis (Raghunath 2012).

\section{HPLC analysis:}

The extract obtained was run on HPLC unit to detect the presence of lovastatin using C18 column. The retention time was noted by comparing with the HPLC chromatogram of standard lovastatin.

\section{Antifungal activity of lovastatin:}

Sterile Petri plates containing potato dextrose agar were swabbed with suspension of test organism Sacchromyces cerevisiae. 
For studying antifungal activity, the wells were made on these plates with the help of sterile borer ( 5 $\mathrm{mm}$ diameter). Fungal extract 100 micro liters was poured in wells and control acetonitrile as negative and positive control was standard lovastatin (Merk) $1 \mathrm{mg} / \mathrm{ml}$ was maintained. The plates were incubated at $25^{\circ} \mathrm{C}$ for $16-25 \mathrm{hrs}$ and the zone of inhibition were noted following incubation.

\section{RESULTS AND DISCUSSION:}

In present investigation evaluated antifungal potential of secondary metabolite extracted from endophyte fungus Preussia sp. isolated from Azadirachta indica was studied (Fig.1 A). Many endophytic fungi have been isolated earlier from Azadirachta indica by Kharwar et al (2011).

Identification of Fungus: The endophytic fungus isolated from Neem tree was characterized culturally and morphologically. On the basis of cultural and morphological studies the isolated fungus labeled $\mathrm{N}_{2} \mathrm{~L}_{5} \mathrm{BLC}$ was identified as member of Preussia isabellae.

Colonies on PDA showed white to cream colored appearance that eventually changes from cream to black (Fig.1 B, C). Microscopic examination exhibits short ornamental hyphae pseudothecia globose, subglobose to pyriformes asci eight spored, ascospores cylindrical, rectangular, dark (Fig.2).

In this investigation, lovastatin a secondary metabolite produced by endophyte from Neem tree was evaluated. Secondary metabolites from endophytes of medicinal plants have been reported by researchers. Endophyte from Taxus baccata has been isolated by Raghunath (2012) with cytotoxic secondary metabolites.

Extraction of lovastatin: HPLC analysis of the extract of identified $P$. isabellae for detection of lovastatin shows presence of peak that matches with peak obtained from standard lovastatin with retention time of 24 minutes (Graph 1). From peak the concentration of lovastatin was estimated as $2.11 \mathrm{mg} / 1$.

Antifungal activity: After incubation a clear zone of inhibition was observed around the well containing fungal extract indicating the antifungal activity of the fungi against Sacchromyces cerevisiae. Zone of clearance obtained for $P$. isabellae extract was measured as $26.66 \mathrm{~mm}$ while lovastatin standard cleared a zone of inhibition of $22.3 \mathrm{~mm}$ of diameter (Fig. 3).

Antifungal studies from Fungi have been reported by Cabral (2010). The antifungal activity of statins like simvastatin and atorvastatin on few Candida species and Aspergilus fumigatus have been reported effectively (Macreadie, 2006). An endophytic fungus Preussia isabellae isolated from Azadirachta indica prominently showed antifungal activity against Sacchromyces cerevisiae with considerable zone of inhibition.

\section{CONCLUSION:}

From the study it has been concluded that fungal endophyte of Azadirachta indica is good source endophytes which are having potential source of pharmaceutically important secondary metabolites, lovastatin is one such compound extracted from endophytic fungus Preussia isabellae isolated from Azadirachta indica. There is need to explore this plant for more endophytes and their secondary metabolites.

\section{REFERANCE :}

Buemi M, Senatore M, Corica F, Aloisi C, Romeo A, Cavallaro E, et al. Statins and progressive renal disease. Med Res Rev. 2002; 22:76-84

Cabral ME, Delgado OD, Sampietro DA, Catalan CA, Figueroa LIC, Farina JI . Antifungal Activity and the potential Coorelation with Statin-Producing ability:An Optimized screening applied to Filamentous Fungi from Las Yungag Subtropical Rainforest. Research Journal of Microbiology 2010; 5 9:833-848.

Kharwar RN,Verma VC, Gond SK, Harper JK, Hess WM, Ma C, Ren Y, Strobel GA Javanicin an antibacterial Naphthaquinone from endophytic fungus of Neem,Chloridium sp." Current Microbiology 2009; 58:233-238.

Raghunath R, Radhakrishna A, Angayarkarnni J,Palaniswamy M. Production and cytotoxicity studies of lovastatin from Aspergillus niger an endophytic fungi isolated fromTaxus baccata. Int.J .of Appl.Biol And pharm.Tech 2012; 3(3):342-351.

Schulz,B.,Wanke, U. Draeger, S, Aust, H. J.C(1993). Endophytes from Herbaceous plants and shrub: effectiveness of surface sterilization method. Mycological Research. 97: 1447-1450. 
Strobel G, Daisy B. Bioprospecting for Microbial Endophytes and their natural Products. Microbiology and Molecular Biology Reviews 2003; 67.4.491-502.

Arenal F, Platas G, and Peláez F. A new endophytic species of Preussia (Sporormiaceae) inferred from morphological observations and molecular phylogenetic analysis Fungal Diversity 2007; 25: 1-17.
Tejesvi, Pirttil A and. Frank ,A Endophytes Potential of Tree Endophytes as Sources for New Drug Compounds of Forest Trees: Biologyand Applications, 1599-8 182011

Macreadie IG,Johnson Schlosser T, Macreadie PI(2006) Growth inhibition of Candida species and Aspergilus fumigatus by statins.FEMS Microbiol Lett262:9-13
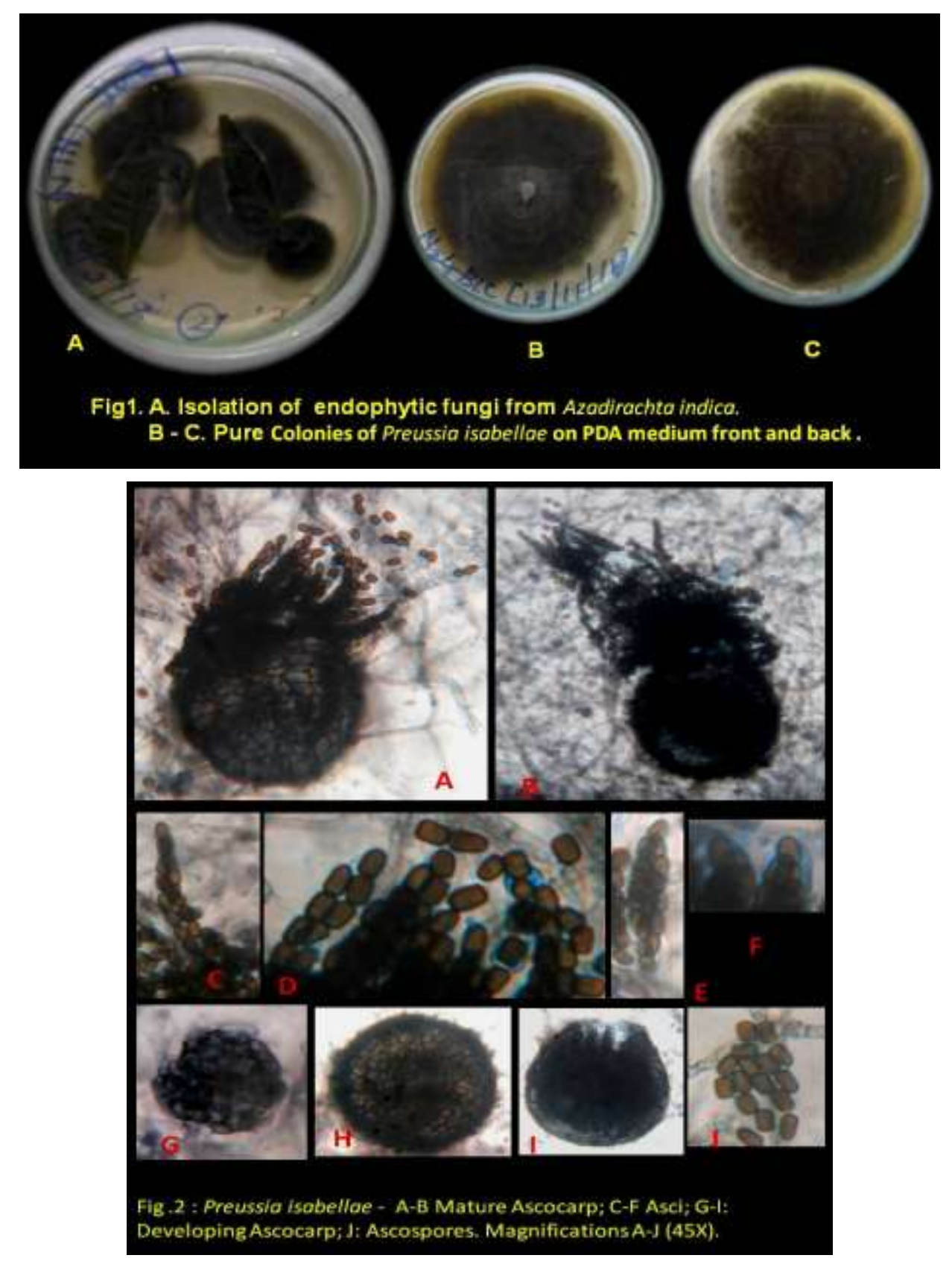


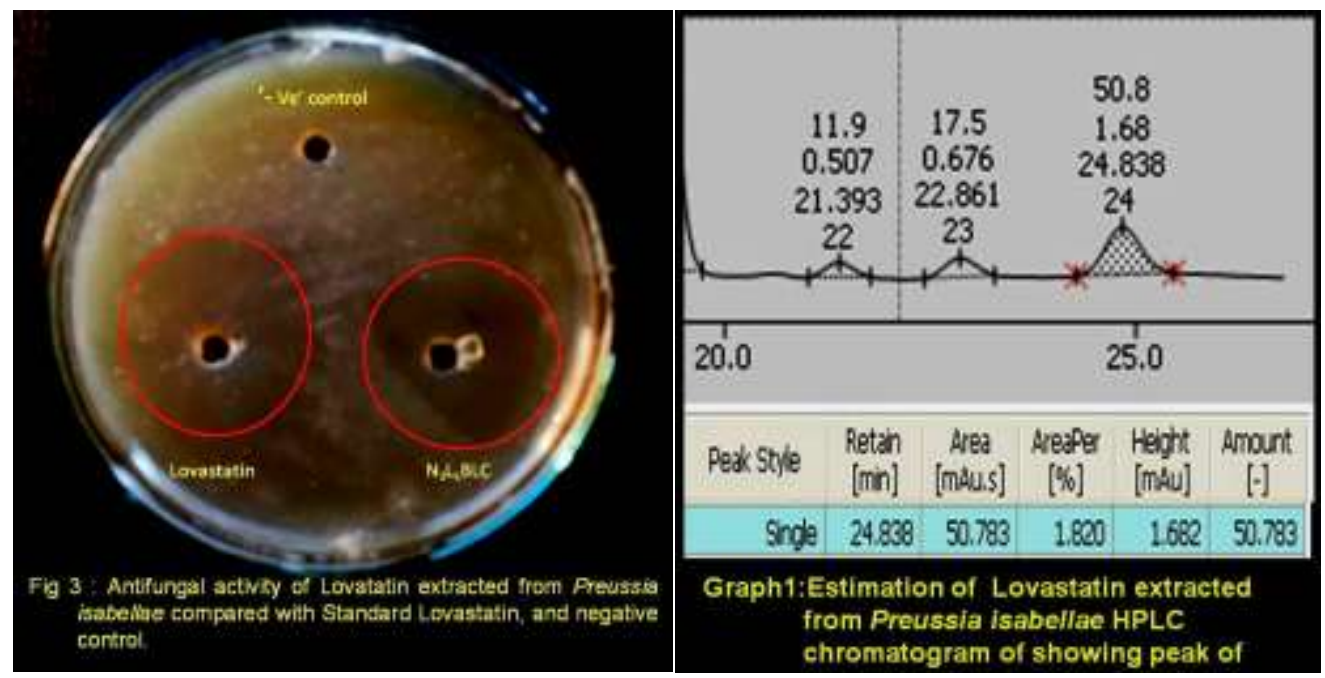

